\title{
Intestinal transit in healthy Southern Indian subjects and in patients with tropical sprue
}

\author{
V JAYANTHI, A CHACKO, I KARIM GANI, AND V I MATHAN \\ From the Wellcome Research Unit and Department of Gastroenterology, Christian Medical College \& Hospital, \\ Vellore, India
}

SUMMARY Whole gut transit was measured in a group of 21 healthy volunteers and 21 patients with tropical sprue by radio-opaque marker technique, using mean transit time single (MTTS) and single stool transit (SST) method. Mean SST in controls was $25.8(1.4)(\mathrm{SE})$ hours, which is considerably shorter than in controls in temperate zones. Mean SST $(23 \cdot 7(0 \cdot 6)$ h) correlated significantly with average MTTS $(24.9(1.6) \mathrm{h})(\mathrm{r}=0.88 ; \mathrm{p}<0.001)$ confirming that SST is a valid method to measure intestinal transit in the tropics. Patients with tropical sprue had a mean SST similar to controls $(24 \cdot 4$ $(1 \cdot 1) \mathrm{h})$, in spite of significantly higher faecal weights $(580(41 \cdot 2) \mathrm{g} v 252(17 \cdot 2) \mathrm{g} ; \mathrm{p}<0 \cdot 001)$.

\begin{abstract}
Variability in intestinal transit in different population groups may have considerable epidemiological significance because gut transit has been shown to be important in regulating intestinal function. ${ }^{12}$ Many of the published reports of intestinal transit are now considered unsatisfactory because of inaccuracies introduced by a high degree of variability in the methods used. ${ }^{3}$ Though the possibility of changes in gut transit in patients with tropical sprue has been suggested ${ }^{45}$ the role of transit in the diarrhoea of malabsorption is not fully understood. Therefore we measured whole gut transit in a group of patients with tropical sprue and a matched group of asymptomatic controls, using two methods, mean transit time single (MTTS) and single stool transit (SST), which have been validated by a continuous steady state marker excretion technique. ${ }^{67}$
\end{abstract}

\section{Methods}

PATIENTS AND SUBJECTS

Twenty one healthy, asymptomatic adults (10 men and 11 women) aged 16-60 years (median age 35 years) and 21 patients with tropical sprue (12 men and nine women) aged 17-58 years (median age 32 years) from villages around Vellore, were studied.

Address for correspondence: Dr A Chacko, The Wellcome Research Unit, CMC Hospital, Vellore 632004, India.

Received for publication 29 June 1988.
The study lasted 14 days during which time the subjects lived in a metabolic ward. Throughout the study, all subjects were fed a controlled diet similar to the diet in rural areas. The basic daily diet of about $10.9 \mathrm{MJ}$ consisted of $60 \mathrm{~g}$ of protein, $50 \mathrm{~g}$ of fat and $450 \mathrm{~g}$ of carbohydrate with $30 \mathrm{~g}$ of dietary fibre. All dietary intakes except fibre were calculated from Nutrition value of Indian foods (NIN, ICMR, Hyderabad) $1985 .{ }^{8}$ Fibre content of diet was measured as neutral detergent fibre. ${ }^{9}$ During the first week (equilibration period) all subjects were investigated as described elsewhere ${ }^{4}$ to confirm the diagnosis of tropical sprue and to exclude other conditions. None of the healthy volunteers gave a history of diarrhoea for the preceding two months and all had normal faecal fat ${ }^{10}$ (mean (SE), 3.6 (0.23); range 1.8-5.6 g/d) and vitamin $B_{12}$ absorption ${ }^{11}(0 \cdot 87$ $(0 \cdot 09)$; range $0 \cdot 2-1 \cdot 5 \%$ dose/l). Five of the controls had low urinary xylose excretion ${ }^{12}(26 \cdot 3(2 \cdot 3) \%$; range $8 \cdot 5-41 \cdot 8 \%$ ) which is part of tropical enteropathy found in apparently healthy asymptomatic southern Indian villagers ${ }^{13}$ and plays no role in nutrient absorption. ${ }^{14}$

MEASUREMENT OF WHOLE GUT TRANSIT

Mean transit time single (MTTS) and single stool transit (STT) were estimated during the second week (study period) while the subjects were in the metabolic ward by the methods of Cummings et al. ${ }^{67}$ Briefly, 20 markers each of a specific shape were 


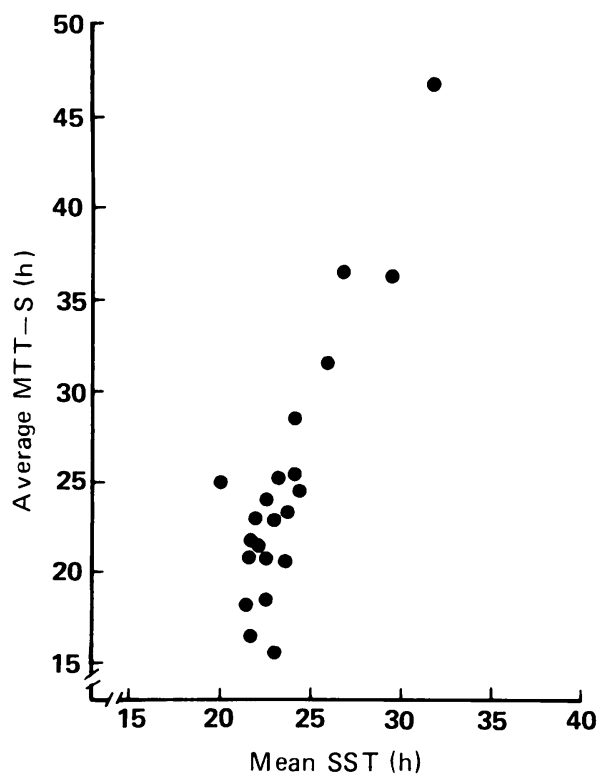

Fig. 1 Correlation between average MTTS and mean SST $(n=22, y=2.38 \times-31 \cdot 48, r=0.88, p<0.001)$.

given on three successive days with breakfast. The radio-opaque markers, barium sulphate impregnated polyethylene pellets, used in the study were cubes (mean weight (MW) $7.8 \mathrm{mg}$, specific gravity (SG) 1.25 ), small circles (MW 8.0 mg, SG 1.63), and large circles (MW 16.0 mg, SG 1.63). Every stool passed after giving the first dose of marker was collected in a polyethylene bag, the time noted, the stool $x$-rayed and the number of each marker present counted. This was continued until all the markers given were recovered.

Single stool transit was calculated from the

Table Whole gut transit in southern Indian volunteer controls and patients with tropical sprue

\begin{tabular}{|c|c|c|c|}
\hline \multirow{2}{*}{$\begin{array}{l}\text { Method } \\
\text { Single stool } \\
\text { transit (SST) }\end{array}$} & \multicolumn{3}{|c|}{ Whole gut transit time $(h)$ mean $(S E)$} \\
\hline & $\begin{array}{l}\text { Southern } \\
\text { Indian } \\
\text { volunteer } \\
\text { controls }\end{array}$ & $\begin{array}{l}\text { Tropical } \\
\text { sprue }\end{array}$ & $\begin{array}{l}\text { Western controls } \\
\text { (Cummings et al } \\
\text { Gut 1976; 17: } \\
\text { 219-23) }\end{array}$ \\
\hline Day 2 & $21.95(0.45)$ & $22.03(0.46)$ & $41 \cdot 87$ \\
\hline Day 3 & $26.08(1.08)$ & $24.35(1.51)$ & 52.93 \\
\hline Day 4 & $30 \cdot 0(3 \cdot 06)$ & $28.33(2.55)$ & $60 \cdot 3$ \\
\hline Mean-SST & $25 \cdot 77(1 \cdot 38)$ & $24.44(1.06)$ & \\
\hline Average MTT-S* & $26.74(2.52)$ & $23.08(1.81)$ & $66 \cdot 06$ \\
\hline Mean-SST $\dagger$ & $24 \cdot 21(1 \cdot 03)$ & $23 \cdot 16(0 \cdot 55)$ & \\
\hline
\end{tabular}

*Average MTTS was done only on 11 patients with sprue and 11 matching controls; † Mean-SST for 11 subjects in each group in whom average MTT-S was estimated. first stool passed after rising on days 2, 3, and 4 separately. ${ }^{7}$ In the majority of subjects there were no markers present in the stools on days 5 and 6 , indicating almost complete marker excretion by day 4. Four of the subjects studied did not excrete markers in the first stool passed after rising on day 2 , one on day 3 , and five on day 4 . Therefore, mean single stool transit (mean-SST) was calculated as the average of the SST values on days 2, 3, and 4 in each subject.

Whole gut transit time was also estimated by the mean transit time single (MTTS) method for each marker separately ${ }^{7}$ in 11 controls and 11 patients with tropical sprue. The average of the MTTS values for the three markers was calculated as average MTTS.

Informed consent was obtained from each subject and the protocol was approved by the Research Committee of the Institution. Statistical analysis was done by Student's $t$ test and correlation and linear regression were done using the Epistat package for microcomputers.

\section{Results}

Single stool transit calculated from day 2, 3, and 4 stool correlated significantly with average MTTS $(\mathrm{p}<0.001$ in all cases). Mean SST (23.7 hours (SE) $0 \cdot 6$, range $20 \cdot 0-31 \cdot 7 \mathrm{~h}$ ) correlated significantly with average MTTS $(24.9 \mathrm{~h}(1.6)$, range $15.5-46.88 \mathrm{~h})$ in the 22 subjects (11 controls and 11 tropical sprue) in whom transit was measured by both methods $(\mathrm{r}=0.88 ; \mathrm{p}<0.001)$ (Fig. 1). The correlation was still significant when each group of subjects were considered separately.

The transit time (mean SST) in controls (25.8 (SE) $1 \cdot 4$, range $20.9-45.8 \mathrm{~h}$ ) was longer than in patients with tropical sprue $(24.4(1 \cdot 1) \mathrm{h}$; range $20 \cdot 0-42.7 \mathrm{~h})$. But the differences were not significant for any of the calculated values, SST on day 2, 3, and 4, mean SST or average MTTS (Table).

Mean daily faecal wet weight in patients with tropical sprue (580 $(41 \cdot 2) \mathrm{g}$; range $348-898 \mathrm{~g})$ was significantly higher than in controls $(252(17 \cdot 2) \mathrm{g}$; range $142-454 \mathrm{~g})(\mathrm{p}<0 \cdot 001)$. There was no correlation between faecal wet weight and transit times both in controls and patients with sprue (Fig. 2).

\section{Discussion}

The correlation between average MTTS and mean SST in the present study confirms that SST is a valid method to measure gut transit. When SST was calculated for each day, SST of day 4 correlated best with MTTS. Five of the 22 controls excreted no markers on day 4 , however, and if there were no other data, transit could not have been calculated. 


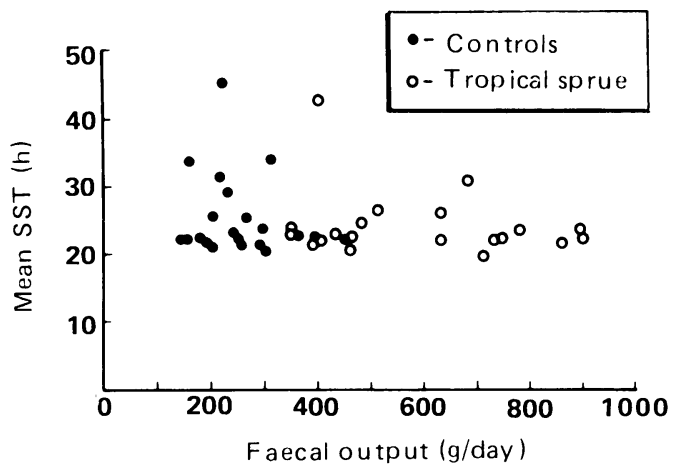

Fig. 2 Faecal output and mean SST in Southern Indian controls and patients with tropical sprue $(r=0 \cdot 19, p=0 \cdot 227)$.

This is presumably related to the considerably shortened transit time in Indians compared with subjects in the West (Table). The results indicate that when SST method is used to measure gut transit in populations with a shorter transit than in temperate climates it is necessary to estimate mean SST.

This study as well as other published reports from India ${ }^{15-17}$ confirm that intestinal transit is considerably shorter in Indians compared with residents of temperate zones. Shortened transit time is primarily attributed to increased faecal bulk and high consumption of dietary fibre. ${ }^{18}$ The mean faecal weight of control subjects in the present study is high ${ }^{19}$ and may contribute to the shortened transit time. The dietary fibre intake in the present study $(30 \mathrm{~g} /$ day estimated as neutral detergent fibre) is higher than in the United Kingdom, ${ }^{20}$ and may also have contributed to the fast transit.

Although fibre has been shown to play an important role in shortening transit, ${ }^{18}$ its role in the tropics has been questioned. ${ }^{17}$ The role of other dietary factors like spices and environmental factors are not known. Poorly understood biological factors may also influence transit as it has been shown that Japanese living in Honolulu and eating a Western type of diet have the same short intestinal transit as Japanese living in Japan and consuming a high fibre diet. ${ }^{21}$ The differences in transit time between the studies from India ${ }^{15-17}$ may be because of dietary or biological differences between populations.

The control subjects in the present study have similar whole gut transit in spite of the wide range of faecal weights (142-454 g/day). Faecal bulk is considered to be an important factor in regulating gut transit.' Burkitt et al ${ }^{18}$ have reported that intestinal transit decreases rapidly when faecal weights increase from $20-30 \mathrm{~g} /$ day to about $120-200 \mathrm{~g} /$ day and a further increase causes little or no change in transit time. The lack of correlation between faecal weights and transit time in controls may be because the faecal weights fall in the asymptotic part of the curve correlating faecal weights with transit times. It is usually believed that transit is the result rather than the cause of colonic events. Cummings et al, ${ }^{\prime}$ however, have shown interesting evidence to support the view that transit itself influences events in the human large intestine and may independently modify the effect of dietary factors on the gut. If this view is taken, it could be assumed that transit time may be one of the major determinants of faecal weight. The study by Burkitt $e t a l^{18}$ may then be interpreted to mean that the cause for the sharp increase in faecal weight from 30 to $200 \mathrm{~g} /$ day is the decrease in transit time from $120 \mathrm{~h}$ to 40 hours. At transit times below 40 hours, however, there is a wide variation in faecal weights (200-500 g/day) without a significant change in transit time. The mechanism by which the latter occurs is not clear. The relation between transit times and faecal weights of the control group in the present study is similar to the findings of Burkitt $e$ et $a l^{18}$ when they fed rural African adults a high fibre diet.

Whole gut transit was measured in patients with tropical sprue to investigate the role of transit in the pathogenesis of diarrhoea in these patients. Previous studies $^{45}$ have shown that small intestinal transit is prolonged in patients with tropical sprue, probably secondary to stimulation of ileal brake mechanism by malabsorbed fats and proteins. ${ }^{22}$

Although there is a striking increase in stool weights in tropical sprue, there is no change in whole gut transit time as compared with controls. This could be because of a combination of prolonged small intestinal transit in tropical sprue ${ }^{45}$ together with acceleration of colonic transit. This may not be the sole explanation, however, as small gut transit contributes to less than $15 \%$ of whole gut transit. ${ }^{23}$ The study by Burkitt $e a^{18}{ }^{18}$ and our own data suggest, that at transit times below 40 hours, there may be a dilatation of the colon with accommodation of faeces giving rise to a wide variability of faecal weights with similar transit times. It is possible that the accommodation limit of the colon is not exceeded in the tropical sprue patients studied, resulting in transit times similar to controls. Further, the prolonged small intestinal transit in tropical sprue may play a complimentary role reducing the volume of material entering the colon per unit time. It may be difficult to determine the precise role of transit in the diarrhoea of tropical sprue as morphological and functional abnormalities of the colon have also been shown in this disease..$^{24}$

\section{References}

1 Cummings $\mathrm{JH}$. Consequences of the metabolism of 
fibre in the human large intestine. In: Vahouny GV, Kritchevsky D, eds. Dietary fibre in health and disease. New York: Plenum Press, 1982: 11-4.

2 Holgate AM, Read NW. Relationship between small bowel transit time and absorption of a solid meal. Influence of metoclopramide magnesium sulphate and lactulose. Dig Dis Sci 1983; 28: 812-9.

3 Cummings JH. Diet and transit through the gut. J Plant Foods 1978; 3: 83-95.

4 Baker SJ, Mathan VI. Tropical sprue in southern India. In: Tropical and megaloblastic anaemia. A Wellcome Trust Collaborative Study. London: Churchill Livingstone, 1971: 189-260.

5 Cook GC. Delayed small intestinal transit in tropical malabsorption. $\mathrm{Br}$ Med J 1978; ii: 238-40.

6 Cummings JH, Jenkins DJA, Wiggins HS. Measurement of mean transit time of dietary residue through the human gut. Gut 1976; 17: 210-8.

7 Cummings $\mathbf{J H}$, Wiggins HS. Transit through the gut measured by analysis of a single stool. Gut 1976; 17: 219 23.

8 Gopalan C, Ramasastri BV, Balasubramanian SC. Nutritive value of Indian foods. Hyderabad: National Institute of Nutrition, Indian Council of Medical Research, 1985.

9 Robertson JB. The detergent system of fibre analysis. IV. Procedures in the detergent system of fibre analysis. In: Spiller GA, ed. Topics in dietary fibre research. New York: Plenum Press, 1978: 18-29.

10 Van de Kamer JH, Huinink Ten B, Weyers HA. Rapid method for determination of fat in the faeces. $J$ Biol Chem 1949; 177: 348-55.

11 Mathan VI, Swarnabai S, Baker SJ. Intestinal absorption of radioactive vitamin B12: a comparison of plasma, fecal and urinary tests. Indian J Med Res 1973; 61: 714 23.

12 Baker SJ, Jacob R, Mathan VI. An evaluation of the $5 \mathrm{~g}$ D-xylose absorption test with fractional urine collections in subjects living in Southern India. Indian J Med Res 1971; 59: 1869-77.
13 Baker SJ, Mathan VI. Tropical enteropathy and tropical sprue. Am J Clin Nutr 1972; 25: 1047-55.

14 Chacko A, Begum A, Mathan VI. Absorption of nutrient energy in southern Indian control subjects and patients with tropical sprue. Am J Clin Nutr 1984; 40: 771-5.

15 Tandon RK, Prasad N, Gupta MC. Stool weights and transit times in north Indians. J Assoc Physicians India 1976; $24: 807$.

16 Patowary AC, Patowary S, Ahmed GG. A study on intestinal transit time of healthy volunteers in Assam. Trop Gastroenterol 1983; 4: 104-8.

17 Shetty PS. Kurpad AV. Intestinal transit time of South Indian subjects. Indian J Med Res 1984; 80: 693-8.

18 Burkitt DP, Walker ARP, Painter NS. Effect of dietary fibre on stools and transit time, and its role in the causation of disease. Lancet 1972; ii: 1408-12.

19 Cummings JH. Physiological aspects of dietary fibre in man. In: Truelove SC, Mayworth MF, eds. Topics in Gastroenterology. Oxford: Blackwell, 1978; 6: 49-62.

20 Bingham SA, Williams DRR, Cummings JH. Dietary fibre consumption in Britain: new estimates and their relation to large bowel cancer mortality. $\mathrm{Br} J$ Cancer 1985; 52: 399-402.

21 Glober GA, Lein KL, Moore JO, Abba BC. Bowel transit times in two populations experiencing similar colon cancer risks. Lancet 1974; ii: 80-1.

22 Read NW, McFarlane A, Kinsman RI, et al. Effect of infusion of nutrient solutions into the ileum on gastrointestinal transit and plasma levels of neurotensin and enteroglucagon. Gastroenterology 1984; 86: 274-80.

23 Read NW, Miles CA, Fisher D, et al. Transit of a meal through the stomach, small intestine, and colon in normal subjects and its role in the pathogenesis of diarrhoea. Gastroenterology 1980; 79: 1276-82.

24 Ramakrishna BS, Mathan VI. Water and electrolyte absorption by the colon in tropical sprue. Gut 1982; 23: 843-6. 